\title{
Impairment in Flow-Mediated Vasodilatation of the Brachial Artery in Acromegaly
}

\author{
Merih Baykan ${ }^{a}$ Cihangir Erem ${ }^{b}$ Ömer Gediklib Arif Hacıhasanoglu ${ }^{b}$ \\ Turan Erdogan $^{\text {b }}$ Mustafa Kocak ${ }^{\text {b }}$ Şahin Kaplan ${ }^{b}$ Levent Korkmaz ${ }^{\text {b }}$ \\ Şükrü Çelik ${ }^{b}$ \\ Departments of a Cardiology and ${ }^{\mathrm{b}}$ Internal Medicine, Division of Endocrinology, Karadeniz Technical University, \\ Trabzon, Turkey
}

\section{Key Words}

Acromegaly $\cdot$ Flow-mediated dilatation $\cdot$ Brachial artery

\begin{abstract}
Objective: The aim of this study was to assess flow-mediated dilatation (FMD) of the brachial artery in patients with acromegaly. Subjects and Methods: We prospectively evaluated 25 patients with acromegaly ( 14 females, 11 males; aged 42 \pm 12 years; growth hormone (GH) levels $34 \pm 14 \mathrm{ng} / \mathrm{ml}$ ) and 27 control subjects ( 15 females, 12 males; aged $45 \pm 8$ years; $\mathrm{GH}$ levels $3 \pm 1.5 \mathrm{ng} / \mathrm{ml}$ ). The patients and controls were matched for age, gender, body mass index, cigarette smoking, blood pressure, lipid levels, diabetes mellitus, hypertension, and its duration. Endothelial function, measured as FMD of the brachial artery using ultrasound, was calculated in the 2 groups. The endothelial function was evaluated by assessing 1-min postischemic FMD of the brachial artery. $\boldsymbol{R e}$ sults: The FMD was lower in patients with acromegaly (9.97 $\pm 3.5 \%)$ than in controls $(16.1 \pm 3.4 \%)$, and the difference was statistically significant $(p=0.0001)$. Conclusion: Endothelial dysfunction may develop in the preclinical phase of atherosclerosis in patients with acromegaly. Endotheliumdependent FMD may be impaired in acromegalic patients, and measurement of endothelial function may identify highrisk individuals earlier.

Copyright @ 2009 S. Karger AG, Basel
\end{abstract}

\section{Introduction}

Acromegaly is characterized by an excess of growth hormone $(\mathrm{GH})$ and insulin-like growth factor (IGF-1) secretion [1]. Acromegaly is associated with a 2- to 3 -fold increase in morbidity and mortality due to cardiovascular disease, which may be a result of the long exposure of tissues to excess GH. In patients with acromegaly, coronary heart disease and hypertension have been shown to be a major cause of increased morbidity and mortality rates [2].

Endothelial dysfunction is an early phase of atherosclerosis and can be measured noninvasively using highresolution ultrasonography to measure postischemic flow-mediated dilatation (FMD) of conduit arteries [3]. Impaired FMD is an early marker of atherosclerotic degeneration, and has been shown to be correlated with coronary endothelial dysfunction [4].

In patients with acromegaly, vascular abnormalities may occur in the absence of the classical risk factors. Increased atherosclerotic risk may be related to abnormal GH secretion in patients with acromegaly [2]. GH stimulates the hepatic production of IGF-1, which mediates GH action on peripheral tissues [5]. GH and IGF-1 promote important effects on the heart and vascular system $[1,5]$. $\mathrm{GH}$ in acromegaly influences the endothelium directly

\section{KARGER}

Fax +4161306 1234

E-Mail karger@karger.ch

www.karger.com
(C) 2009 S. Karger AG, Basel

1011-7571/09/0183-0228\$26.00/0

Accessible online at:

www.karger.com/mpp
Dr. Merih Baykan

Department of Cardiology, Faculty of Medicine

Karadeniz Technical University

TR-61080 Trabzon (Turkey)

Tel. +90 462377 5396, E-Mail merihbaykan@yahoo.com 
via endothelial IGF-1 receptors, or indirectly through effects on lipid metabolism [6]. IGF-1 has effects on the regulation of vascular tone and attenuates vascular contractility [7].

However, it is not clear whether or not endothelial function is impaired in patients with acromegaly. To our knowledge, FMD of the brachial artery has very rarely been investigated in patients with acromegaly [8]. The aim of this study was to assess FMD of the brachial artery in patients with acromegaly and in controls.

\section{Subjects and Methods}

Patients

In the present study, 31 patients ( 16 females, 15 males; aged 43 \pm 10 years) with acromegaly were evaluated. Six patients were excluded: 2 with coronary heart disease, 1 with moderate/severe valvular heart disease, 1 with chronic renal failure, 1 with diabetes mellitus and 1 with atrial fibrillation. The remaining 25 patients with acromegaly ( 12 females, 13 males; aged $42 \pm 12$ years) were matched with 27 control cases ( 13 females, 14 males; aged 45 \pm 8 years) for age, gender, body mass index, blood pressure and hypertension. All patients had a confirmed diagnosis of GH-secreting pituitary adenoma.

The diagnosis of acromegaly was established by the typical clinical signs and symptoms: acral enlargement, hypertension, soft tissue overgrowth, hyperhidrosis, headache, weight gain and/ or acanthosis nigricans; inability to suppress $\mathrm{GH}$ levels below $2 \mu \mathrm{g} / \mathrm{l}$ after ingestion of $75 \mathrm{~g}$ glucose; absence of physiological circadian rhythm; and the presence of serum IGF-1 levels above the normal range. In all patients, imaging of the pituitary was obtained by magnetic resonance imaging (MRI). The MRI confirmed the presence of pituitary adenoma (23 macro- and $2 \mathrm{mi}$ croadenomas). Endocrine study documented a pure GH-secreting adenoma in 24 patients and a $\mathrm{GH}$ - and prolactin-secreting pituitary macroadenoma (mammosomatotropinoma) in 1 patient. All patients were affected by active acromegaly at the time of the study (duration of disease since onset of symptoms: $6.7 \pm$ 5.3 years). All patients underwent microsurgical selective resection of the pituitary adenomas by the transsphenoidal approach; immunohistochemistry confirmed the diagnosis in all patients. Adjuvant radiotherapy and/or medical therapy (octreotide-LAR and cabergoline) were given to the patients with elevated GH and IGF-1 levels after surgery.

The patients had no bundle branch blocks; paced rhythms; atrioventricular blocks; restrictive, hypertrophic or dilated cardiomyopathies; congenital heart disease; hyperthyroidism; hypothyroidism; or poor echocardiographic images. In addition, our patients had no complaints or physical signs of congestive heart failure or coronary heart disease. Electrocardiography showed sinus rhythm with no signs of ischemia in any of the patients.

\section{Flow-Mediated Dilatation}

A standard protocol was used to assess endothelial function, as previously reported [9], according to the recommendations. Briefly, for the FMD of brachial artery, patients fasted $\geq 8 \mathrm{~h}$ before the study. The FMD was evaluated at the same time of the day, at 9.00 a.m., in the acromegalic patients and controls. The study took place in a quiet, temperature-controlled room. Caffeine intake and cigarette smoking were prohibited for at least $4-6 \mathrm{~h}$ before the study. The right arm was immobilized using 2 cushions supporting the elbow and the wrist. A sphygmomanometric cuff was placed on the forearm. After $10-15$ min of rest, the brachial artery was visualized longitudinally with the ultrasonic scanner operating B mode. After an optimal image of the artery was obtained, the ultrasonic transducer was fixed in this position with a custom-built probe holder. Brachial artery diameter was determined manually in end-diastole, indicated by the $\mathrm{R}$ wave of the electrocardiogram. After 3 baseline measurements were obtained, ischemia was induced by the inflation of the cuff to $100 \mathrm{~mm} \mathrm{Hg}$ greater than the systolic arterial pressure to occlude arterial flow for $5 \mathrm{~min}$. After the deflation of the cuff, diameter measurements were performed at $30 \mathrm{~s}$ and 1, 2, 3 and $4 \mathrm{~min}$. Following this, we used FMD at $1 \mathrm{~min}$ after ischemia to represent the spontaneous endothelial function. Maximal obtained diameter during ischemia-induced hyperemia was used for the calculation of the percentage of FMD (maximum diameter - baseline diameter)/baseline diameter $\times 100$. The endothelial function study was performed by 2 experienced operators. The intraobserver and interobserver reproducibilities of resting arterial diameter were $0.01 \pm 0.01$ and $0.01 \pm 0.02 \mathrm{~mm}$, respectively.

\section{Biochemical Assays}

Blood was collected in the morning between 08:00 and 09:00 a.m. after an overnight fast to avoid differences in diurnal variation, especially in hormonal parameters. Chemiluminescent immunometric assay (Immulite 2000 DPC, Diagnostic Products, Los Angeles, Calif., USA) was used to measure serum GH and IGF-1 levels. The normal range for serum GH was $<5 \mathrm{ng} / \mathrm{ml}$. The normal range for IGF-1 was age- but not sex-adjusted (21-25 years: $116-358 ; 26-30$ years: $117-329 ; 31-35$ years: $115-307 ; 36-40$ years: $109-284$; $41-45$ years: $101-267 ; 46-50$ years: $94-252 ; 51-55$ years: $87-238$; $56-60$ years: $81-225$; $61-65$ years: $75-212 ; 66-70$ years: $69-200$; 71-75 years: $64-188$; 76-80 years: $59-177 \mathrm{ng} / \mathrm{ml})$. Other biomarkers of vascular disease (high-sensitivity CRP test, homocysteine, adhesion molecules) were not measured.

\section{Statistical Analysis}

All the results are expressed as means \pm SD. Baseline and echocardiographic variables were compared by $\chi^{2}$ tests for categorical variables and Student's t tests for continuous variables. Pearson correlation coefficients were used for calculation. A value of $\mathrm{p}<0.05$ was considered statistically significant.

\section{Results}

The baseline characteristics of the patients and control subjects are listed in table 1 . There were no significant differences between patients with acromegaly and controls regarding age, gender, smoking, dyslipidemia, body mass index, fasting serum glucose levels, hypertension, duration of hypertension and antihypertensive treatment. 
Table 1. Clinical and laboratory characteristics of the study population

\begin{tabular}{lccl}
\hline & $\begin{array}{c}\text { Patients } \\
(\mathrm{n}=25)\end{array}$ & $\begin{array}{c}\text { Controls } \\
(\mathrm{n}=27)\end{array}$ & $\mathrm{p}$ \\
& $42 \pm 12$ & $45 \pm 8$ & n.s. \\
\hline Age, years & $14 / 11$ & $15 / 12$ & n.s. \\
Women/men & 1 & 2 & n.s. \\
Smokers & $29 \pm 2.1$ & $27 \pm 1.9$ & n.s. \\
Body mass index & $135 \pm 2$ & $132 \pm 3$ & n.s. \\
SBP, mm Hg & $88 \pm 3$ & $86 \pm 2$ & \\
DBP, mm Hg & $83 \pm 7$ & $82 \pm 6$ & n.s. \\
Pulse rate, bpm & $4 / 21$ & $4 / 23$ & n.s. \\
Hypertensive/normotensive & $86 \pm 7$ & $83 \pm 6$ & n.s. \\
$\quad$ patients & $206 \pm 35$ & $205 \pm 32$ & n.s. \\
Fasting serum glucose, mg/dl & $162 \pm 80$ & $165 \pm 90$ & n.s. \\
Total cholesterol, mg/dl & $49 \pm 10$ & $48 \pm 10$ & n.s. \\
Triglycerides, mg/dl & $147 \pm 31$ & $148 \pm 38$ & n.s. \\
HDL cholesterol, mg/dl & $34 \pm 14$ & $3 \pm 1.5$ & 0.0001 \\
LDL cholesterol, mg/dl & $755 \pm 550$ & $150 \pm 32$ & 0.0001 \\
GH, ng/ml & 1 & 1 & n.s. \\
IGF-1, ng/ml & 3 & 3 & n.s. \\
ß-blocker, n & & & \\
Calcium channel blocker, n & 35 & \\
\hline
\end{tabular}

Figures in parentheses are percentages. SBP $=$ Systolic blood pressure; $\mathrm{DBP}=$ diastolic blood pressure; $\mathrm{LDL}=$ low-density lipoprotein; $\mathrm{HDL}=$ high-density lipoprotein.

Table 2. Results of ultrasound measurements of the brachial artery

\begin{tabular}{llll}
\hline & $\begin{array}{l}\text { Patients } \\
(\mathrm{n}=25)\end{array}$ & $\begin{array}{l}\text { Controls } \\
(\mathrm{n}=27)\end{array}$ & $\mathrm{p}$ \\
\hline Baseline diameter, $\mathrm{mm}$ & $0.33 \pm 0.42$ & $0.33 \pm 0.59$ & n.s. \\
$\begin{array}{l}\text { Hyperemia diameter, } \mathrm{mm} \\
\text { FMD, \% }\end{array}$ & $\begin{array}{l}0.36 \pm 0.92 \\
9.97 \pm 3.5\end{array}$ & $0.38 \pm 0.63$ & n.s. \\
\hline
\end{tabular}

Results of ultrasound measurements of the brachial artery are summarized in table 2. FMD was lower in patients with acromegaly than in those without $(9.97 \pm 3.5$ vs. $16.1 \pm 3.4 \%$, respectively; $\mathrm{p}=0.0001$ ).

Although our study demonstrated a trend toward a negative correlation between FMD and GH levels, the difference did not reach statistical significance. No correlation was observed between IGF-1 and FMD. In addition, we did not find any correlation between lipid profiles and FMD in the 2 groups.

\section{Discussion}

Acromegaly contributes to an increased risk of cardiovascular morbidity and mortality (largely from cardiovascular disease, hypertension, peripheral insulin resistance and diabetes mellitus) compared to the normal population [2]. Chronic hypersecretion of GH is associated with intrinsic cardiovascular abnormalities, including myocardial hypertrophy and hyperkinetic heart syndrome [8].

Coronary heart disease has been poorly studied in patients with acromegaly due to the necessity of performing invasive procedures. However, postmortem studies have shown the involvement of small vessels and the thickening of the intramural vessels in up to $22 \%$ of patients [10]. Proximal arteries are usually normal, but may be tortuous, enlarged and occasionally stenotic [11]. The GH influences the endothelium directly via endothelial IGF-1 receptors or indirectly through effects on lipid metabolism, and lipid metabolism abnormalities may occur in acromegalic patients. These abnormalities may contribute to the development of atherosclerosis and increase cardiovascular risk in patients with acromegaly [6]. In addition, GH/IGF-1 are vascular growth factors and, through stimulation of collagen deposition, may have a role in atherosclerosis in acromegalic patients [12]. Although our study demonstrated a trend toward a negative correlation between FMD and GH levels, the difference did not reach statistical significance.

The endothelium plays a key role in vascular homeostasis through the release of a variety of autocrine and paracrine substances. There is some evidence that impairment of endothelium-dependent vasodilatation is an early phenomenon of atherogenesis, and that it is present before the anatomical evidence [13]. Endothelium-derived nitric oxide is a potent vasodilator and plays an important role in the control of vascular tone. It also has antithrombotic and fibrinolytic functions [14]. Endothelial dysfunction predisposes patients to thrombosis, leukocyte adhesion and proliferation of smooth muscle cells in the arterial wall [15], which is associated with abnormal nitric oxide physiology [16]. Impaired FMD is an early marker of atherosclerotic degeneration, and has been shown to be correlated with the extent and severity of coronary artery disease [17]. Endothelial dysfunction can be measured noninvasively by ultrasound and Doppler techniques to detect postischemic FMD of the brachial artery [9]. Conduit artery endothelial dysfunction is associated with abnormal vasomotor responses of coronary circulation $[17,18]$ and impairment in FMD of the bra- 
chial artery of patients with coronary and peripheral arterial disease, without angiographically evident disease [18-20]. Our study showed that FMD of the brachial artery was reduced in acromegalic patients.

Little is known about the endothelial function and FMD of the brachial artery in patients with acromegaly [8]. In the present study, we found impaired FMD of the brachial artery in this group of patients. The precise mechanism of endothelial dysfunction in acromegaly is not well understood. Morphologic and functional alterations of vascular smooth muscle cells may lead to impaired vasoreactivity of the brachial artery. GH excess may play a role in generating endothelial dysfunction, and elevated levels of GH/IGF-1 may directly influence the vascular wall. The vascular defect may be reversible, at least in its earlier manifestation. Ferns et al. [21] showed that IGF, a potent mitogen for vascular smooth muscle cells, was found in atherogenesis. However, IGF may exhibit an inverse correlation with cardiovascular risk and might be protective by increasing nitric oxide production [22]. Brevetti et al. [8] showed impaired FMD of the brachial artery in patients with acromegaly. In cured acromegalic patients, FMD was significantly lower than in healthy controls, but higher than in active patients. GH influences the endothelium indirectly through lipid abnormalities. The abnormalities of lipid metabolism may promote the development of endothelial dysfunction and atherosclerosis in patients with acromegaly [6]. In addition, GH per se acutely affects vascular function [23]. The explanation of our finding may be that the growth effect of GH/IGF-1 is largely outweighed by the antiatherogenic activity of IGF-1 through the PI3-Akt-eNOS pathway.

Cigarette smoking and medications such as angiotensin-converting-enzyme inhibitor, angiotensin II receptor blocker, calcium channel blocker, $\beta$-blockers or statins may affect endothelial function $[24,25]$. Nevertheless, in our study, there were no significant differences regarding the calcium channel blocker and $\beta$-blocker treatment between the patients and controls. The patients and control subjects were not given angiotensin-converting enzyme inhibitor, angiotensin II receptor blocker or statin therapy.

\section{Limitations}

Firstly, hypertension may affect endothelial function. However, matching patients with acromegaly on blood pressure values, duration of hypertension and antihypertensive therapy showed no significant differences regarding hypertension/antihypertensive treatment. Secondly, the existence of coronary heart disease cannot be ruled out because no invasive stress test or angiography was performed; however, there was no clinical, electrocardiographic or echocardiographic ischemic evidence of this. Another limitation was the lack of assessment of nitrateinduced vasodilatation, but, in a previous study, no difference between the groups was observed for endothelium-independent vasodilatation [13].

\section{Conclusion}

The results of this study showed that endothelial dysfunction may develop in the preclinical phase of vascular disease in patients with acromegaly. Measurement of endothelial function of the brachial artery may be useful in identifying high-risk acromegalic patients. Strategies to reduce or retard endothelial dysfunction in patients with acromegaly may lead to decreased cardiovascular morbidity and mortality.

\section{References}

1 Colao A, Marzullo P, Di Somma C, Liombardi G: Growth hormone and the heart. Clin Endocrinol 2001;54:137-154.

-2 Bengtsson B, Eden S, Ernest I, Oden A, Sjogren B: Epidemiology and long-term survival in acromegaly. Acta Med Scand 1988;223: 327-335.

3 Celermajer DS, Sorensen KE, Gooch VM, Spiegelhalter DJ, Miller OI, Sullivan ID, Lloyd JK, Deanfield JE: Non-invasive detection of endothelial dysfunction in children and adults at risk of atherosclerosis. Lancet 1992;340:1111-1115.
-4 Neunteufl T, Heher S, Katzenschlager R, Wölfl G, Kostner K, Maurer G, Weidinger F: Late prognostic value of flow-mediated dilatation in the brachial artery of patients with chest pain. Am J Cardiol 2000;86:207-210.

$\checkmark 5$ Sowers JR: Insulin and insulin-like growth factor in normal and pathological cardiovascular physiology. Hypertension 1997;29: 691-699.

6 Tan KC, Shiu SW, Janus ED, Lan KS: LDL subfractions in acromegaly: relation to growth hormone and insulin-like growth hormone-1. Atherosclerosis 1997;129:59_ 65.
7 Walsh MF, Barazi M, Pete G, Muniyappa R, Dunbar JC, Sowers JR: Insulin-like growth factor 1 diminishes in vivo and in vitro vascular contractility: role of vascular nitric oxide. Endocrinology 1996;137:1798-1803.

-8 Brevetti G, Marzullo P, Silvestro A, Pivonell R, Oliva G, di Soma C, Lombardi G, Colao A: Early vascular alterations in acromegaly. J Clin Endocrinol Metab 2002;87:3174-3179. 
\9 Corretti MC, Anderson TJ, Benjamin EJ, Celermajer D, Charbonneau F, Creager MA, Deanfield J, Drexler H, Gerhard-Herman M, Herrington D, Vallance P, Vita J, Vogel R; International Brachial Artery Reactivity Task Force: Guidelines for the ultrasound assessment of endothelial-dependent flow-mediated dilatation of the brachial artery: a report of the International Brachial Artery Reactivity Task Force. J Am Coll Cardiol 2002;39: 257-265.

10 Lie JT: Pathology of the heart in acromegaly: anatomic findings in 27 autopsied patients. Am Heart J 1980;100:41-52.

11 Chen Y, Capron L, Magnusson JO, Wallby LA, Arnquist HJ: Insulin-like growth factor1 stimulation vascular smooth muscle cell proliferation in rat aorta in vivo. Growth Horm IGF Res 1998;8:299-303.

12 Bruel A, Oxlund H: Biosynthetic growth hormone increases the collagen deposition rate in rat aorta and heart. Eur J Endocrinol 1995;132:195-199.

-13 Sorensen KE, Celermajer DS, Georgakopoulos D, Hatcher G, Betteridge DJ, Deanfield JE: Impairment of endothelium-dependent dilatation is an early event and is related to the lipoprotein(a) level. J Clin Invest 1994;93: $50-55$.
14 Tribe RM, Poston L: Oxidative stress and lipid in diabetes: a role in endothelium vasodilator dysfunction. Vasc Med 1996;1:195206.

15 Ross R: The pathogenesis of atherosclerosis: a perspective for the 1990s. Nature 1993;362: 801-809.

16 Rubanyi GM: The role of endothelium in cardiovascular homeostasis and diseases. J Cardiovasc Pharmacol 1993;22(suppl 4):S1S14.

7 Neunteufl T, Katzenschlager R, Hassan A, Klaar U, Schwarzacher S, Glogar D, Bauer P, Weidinger F: Systemic endothelial dysfunction is related to the extent and severity of coronary artery disease. Atherosclerosis 1997;129:111-118.

18 Anderson TJ, Uehata A, Gerhard MD, Meredith IT, Knab S, Delagrange D, Lieberman EH, Ganz P, Creager MA, Yeung AC: Close relation of endothelial function in the human coronary and peripheral circulations. J Am Coll Cardiol 1995;26:1235-1241.

19 Brevetti G, Martone VD, de Cristofaro T, Corrado S, Silvestro A, Di Donato AM, Bucur R, Scopacasa F: High levels of adhesion molecules are associated with impaired endothelium-dependent vasodilatation in patients with peripheral arterial disease. Thromb Haemost 2001;85:63-66.
20 Celermajer DS, Sorensen KE, Bull C, Robinson J, Deanfield JE: Endothelium-dependent dilatation in the systemic arteries of asymptomatic subjects relates to coronary risk factors and their interaction. J Am Coll Cardiol 1994;24:1468-1474.

21 Ferns GA, Motani AS, Anggard EE: The insulin-like growth factors: their putative role in atherogenesis. Artery 1991;18:197-225.

22 Conti E, Carrozza C, Capoluongo E, Volpe $\mathrm{M}$, Crea F, Zuppi C, Andreotti F: Insulin-like growth factor-1 as a vascular protective factor. Circulation 2004;110:2260-2265.

23 Li G, Del Rincon JP, Jahn LA, Wu Y, Gaylinn B, Thorner MO, Liu Z: Growth hormone exerts an acute vascular effects independent of systemic or muscle insulin-like growth factor-1. Clin Endocrinol Metab 2008;93:13791385.

24 Corretti MC, Plotnick GD, Vogel RA: Smoking correlates with flow-mediated brachial artery vasoreactivity but not cold pressor activity in men with coronary artery disease. Int J Card Imaging 1998;14:11-17.

25 Anderson TJ, Elstein E, Haber H, Charbonneau F: Comparative study of ACE inhibition, angiotensin II, antagonism, and calcium channel blockade on flow-mediated vasodilatation in patients with coronary disease. J Am Coll Cardiol 2000;35:60-66. 